\title{
PREDIKSI MINAT KONSUMEN SESUAI MUSIM MENGGUNAKAN ALGORITMA K-MEANS PADA PERANGKAT LUNAK PEMESANAN TEMPAT DAN MAKANAN ONLINE
}

\author{
Teguh Nurhadi Suharsono' ${ }^{1)}$, Maulana Akbar ${ }^{2)}$ \\ Program Studi Teknik Informatika ${ }^{12)}$ \\ Universitas Sangga Buana YPKP ${ }^{1)}$, STMIK LPKIA ${ }^{2)}$ \\ teguhns21@ gmail.com ${ }^{1)}$, syncronizationyourwords@gmail.com ${ }^{2)}$
}

\begin{abstract}
ABSTRAK
Banyak menu makanan yang tidak terjual menyebabkan restoran merugi dikarenakan bahan makanan yang ada jadi tidak terpakai. Maka dalam hal ini K-Means dapat digunakan untuk meng-cluster minat konsumen dimana minat tersebut akan disesuaikan dengan musim. Algoritma K-Means akan digunakan pada perangkat lunak untuk menemukan minat konsumen dari data penjualan yang ada, dalam hal ini bisa dikatakan sebagai data mining dimana data tersebut akan dibuat dan diurutkan berdasarkan minat pelanggan seperti musim panas ataupun musim hujan. Dan penentuan permasalahan tadi berdasarkan musim dikarenakan minat konsumen akan lebih mudah dikalkulasikan mengikuti musim yang ada di Indonesia dimana Indonesia sendiri adalah negara beriklim tropis yang dimana memiliki menu makanan yang beragam. Dengan adanya pengelompokan data dari data penjualan diharapkan rumah makan atau restoran dapat menentukan menu makanan dan minuman yang sesuai dengan minat konsumen dimana menu makanan tersebut akan disesuaikan dengan musim yang ada di Indonesia yaitu musim panas dan musim hujan. Dan hasil pengolahan data tadi akan diimplementasikan pada perangkat lunak pemesanan tempat dan makanan online yang sebelumnya sudah dibuat pada penelitian sebelumnya yang berjudul Perangkat Lunak Pemesanan Tempat dan Makanan Online. Hal ini dimaksudkan untuk memudahkan pihak restoran dalam menentukan dalam pengaturan pembelian bahan baku makan. Apabila terdapat menu yang banyak terjual maka bahan baku akan diperbanyak dan apabila terdapat menu makanan yang kurang peminat atau penjualannya terbilang kurang atau sedikit maka bahan baku tersebut akan dikurangi.
\end{abstract}

Kata Kunci : K-Means, Minat, Konsumen, Prediksi, Season.

\section{Pendahuluan}

Banyak perusahaan pada masa sekarang sedang melakukan pembaharuan dalam sistem pemasaran untuk menjual produknya. Berbagai cara dilakukan seperti melakukan kuisioner, iklan, dan bahkan sampai memprediksi minat konsumen. Hal ini dilakukan agar produk yang dijual dapat disesuaikan dan tidak terlalu melenceng dari keinginan konsumen. Ada berbagai cara untuk memprediksi minat konsumen, salah satu contoh adalah menggunakan alat bantu berupa perangkat lunak. Menggunakan perangkat lunak adalah cara yang mudah untuk memprediksi dikarenakan sistem dari perangkat lunak tersebut yang menghitung, mengkalkulasikan dan mengklasifikasikan produk. Dimana salah satunya adalah perangkat lunak dengan menggunakan algoritma dan data mining. Algoritma tersebut akan menentukan pengambilan keputusan mengenai minat dari konsumen berdasarkan data penjualan.

Perangkat lunak yang menggunakan algoritma diharapkan dapat membantu pihak perusahaan untuk mengambil keputusan mengenai minat pelanggan agar produk dapat sesuai dengan keinginan pasar dalam hal ini konsumen. Begitu pula dengan rumah makan dan restoran akan membutuhkan hasil prediksi mengenai minat konsumen untuk menyesuaikan menu makanan dan minuman. Banyaknya jenis makanan dan minuman yang ada di rumah makan atau restoran yang terkadang ada menu yang tidak terjual atau kurang peminat tentunya akan merugikan pihak rumah makan atau restoran. Maka dalam hal ini K-Means dapat digunakan untuk meng-cluster minat konsumen dimana minat tersebut akan disesuaikan dengan 
musim. Algoritma K-Means akan digunakan pada perangkat lunak untuk menemukan minat konsumen dari data penjualan yang ada, dalam hal ini bisa dikatakan sebagai data mining dimana data tersebut akan dibuat dan diurutkan berdasarkan minat pelanggan seperti musim panas ataupun musim hujan. Algoritma K-means clustering sendiri merupakan salah satu metode data clustering non-hirarki yang mengelompokan data dalam bentuk satu atau lebih cluster/kelompok. Data - data yang memiliki karakteristik yang sama dikelompokan dalam satu cluster/kelompok dan data yang memiliki karakteristik yang berbeda dikelompokan dengan cluster/kelompok yang lain sehingga data yang berada dalam satu cluster/kelompok memiliki tingkat variasi yang kecil (S. Agustina, 2012). Dan penentuan permasalahan tadi berdasarkan musim dikarenakan minat konsumen akan lebih mudah dikalkulasikan mengikuti musim yang ada di Indonesia dimana Indonesia sendiri adalah negara beriklim tropis yang dimana memiliki menu makanan yang beragam.

Dengan adanya pengelompokan data dari data penjualan diharapkan rumah makan atau restoran dapat menentukan menu makanan dan minuman yang sesuai dengan minat konsumen dimana menu makanan tersebut akan disesuaikan dengan musim yang ada di Indonesia yaitu musim panas dan musim hujan. Dan hasil pengolahan data tadi akan diimplementasikan pada perangkat lunak pemesanan tempat dan makanan online yang sebelumnya sudah dibuat pada penelitian sebelumnya yang berjudul Perangkat Lunak Pemesanan Tempat dan Makanan Online Food Garden Miko Mall. Penelitian ini merupakan penambahan fitur pada perangkat lunak tersebut dimana perangkat lunak tersebut merubah penerapan cara pemesanan yang pada umumnya pemesanan tersebut dilakukan secara konvensional dimana calon pelanggan harus datang ke Food Garden menjadi pemesanan secara online dengan tidak perlu datang pelanggan sudah dapat memesan tempat melalui website. Fitur tambahan ini berupa menu produk yang disarankan, seperti halnya barang yang sedang hot ataupun barang yang banyak terjual atau barang yang sedang tren seperti pada online shop. Fitur tambahan lainnya berupa laporan permusim untuk menentukan menu makanan yang banyak terjual pada musim panas atau kemarau dan musim penghujan dan menu makanan apa saja yang tidak terjual pada musim hujan dan musim panas tersebut berdasarkan data yang telah diproses oleh K-means berdasarkan cluster yang ditentukan. Hal ini dimaksudkan untuk memudahkan pihak restoran dalam menentukan dalam pengaturan pembelian bahan baku makan. Apabila terdapat menu yang banyak terjual maka bahan baku akan diperbanyak dan apabila terdapat menu makanan yang kurang peminat atau penjualannya terbilang kurang atau sedikit maka bahan baku tersebut akan dikurangi.

\section{Konsep K-Means Clustering}

Data mining proses mencari pola atau informasi menarik dalam data terpilih dengan menggunakan teknik atau metode tertentu. [1]. Tahapan dalam data mining ada 7 , diantaranya : pembersihan data, integrasi data, seleksi data, transformasi data, proses mining, evaluasi pola, presentasi pengetahuan [1].

Pada dasarnya clustering merupakan suatu metode untuk mencari dan mengelompokkan data yang memiliki kemiripan karakteriktik (similarity) antara satu data dengan data yang lain. Clustering merupakan salah satu metode data mining yang bersifat tanpa arahan (unsupervised), maksudnya metode ini diterapkan tanpa adanya latihan (taining) dan tanpa ada guru (teacher) serta tidak memerlukan target output. [2]

K-means clustering merupakan salah satu metode data clustering non-hirarki yang mengelompokan data dalam bentuk satu atau lebih cluster/kelompok. Data-data yang memiliki karakteristik yang sama dikelompokan dalam satu cluster/kelompok dan data yang memiliki karakteristik yang berbeda dikelompokan dengan cluster/kelompok yang lain sehingga data yang berada dalam satu cluster/kelompok memiliki tingkat variasi yang kecil.

a. Pilih jumlah cluster $\mathrm{k}$.

b. Inisialisasi $\mathrm{k}$ pusat cluster ini bisa dilakukan dengan berbagai cara. Namun yang paling sering dilakukan adalah dengan cara random. Pusat-pusat cluster 
diberiduberi nilai awal dengan angkaangka random,

c. Alokasikan semua data/ objek ke cluster terdekat. Kedekatan dua objek ditentukan berdasarkan jarak kedua objek tersebut. Demikian juga kedekatan suatu data ke cluster tertentu ditentukan jarak antara data dengan pusat cluster. Dalam tahap ini perlu dihitung jarak tiap data ke tiap pusat cluster. Jarak paling antara satu data dengan satu cluster tertentu akan menentukan suatu data masuk dalam cluster mana. Untuk menghitung jarak semua data ke setiap titik pusat cluster dapat menggunakan teori jarak Euclidean yang dirumuskan sebagai berikut:

$$
\sqrt{\left(x_{2}^{i}+x_{2}^{j}\right)^{2}+\left(x_{2}^{i}+x_{2}^{j}\right)^{2}+\left(x_{k}^{i}+x_{k}^{j}\right)^{2}}
$$

\section{Dimana :}

$D(i, j)=$ Jarak data ke $i$ ke pusat cluster $j$ $\mathrm{X}(\mathrm{k}, \mathrm{i})=$ Data ke i pada atribut data ke $\mathrm{k}$ $X(k, j)=$ Titik pusat ke $\mathrm{j}$ pada atribut ke $\mathrm{k}$

d. Hitung kembali pusat cluster dengan keanggotaan cluster yang sekarang. Pusat cluster adalah rata-rata dari semua data/ objek dalam cluster tertentu. Jika dikehendaki bisa juga menggunakan median dari cluster tersebut. Jadi ratarata (mean) bukan satu-satunya ukuran yang bisa dipakai.

e. Tugaskan lagi setiap objek memakai pusat cluster yang baru. Jika pusat cluster tidak berubah lagi maka proses clustering selesai. Atau, kembali ke langkah nomor 3 sampai pusat cluster tidak berubah lagi [4

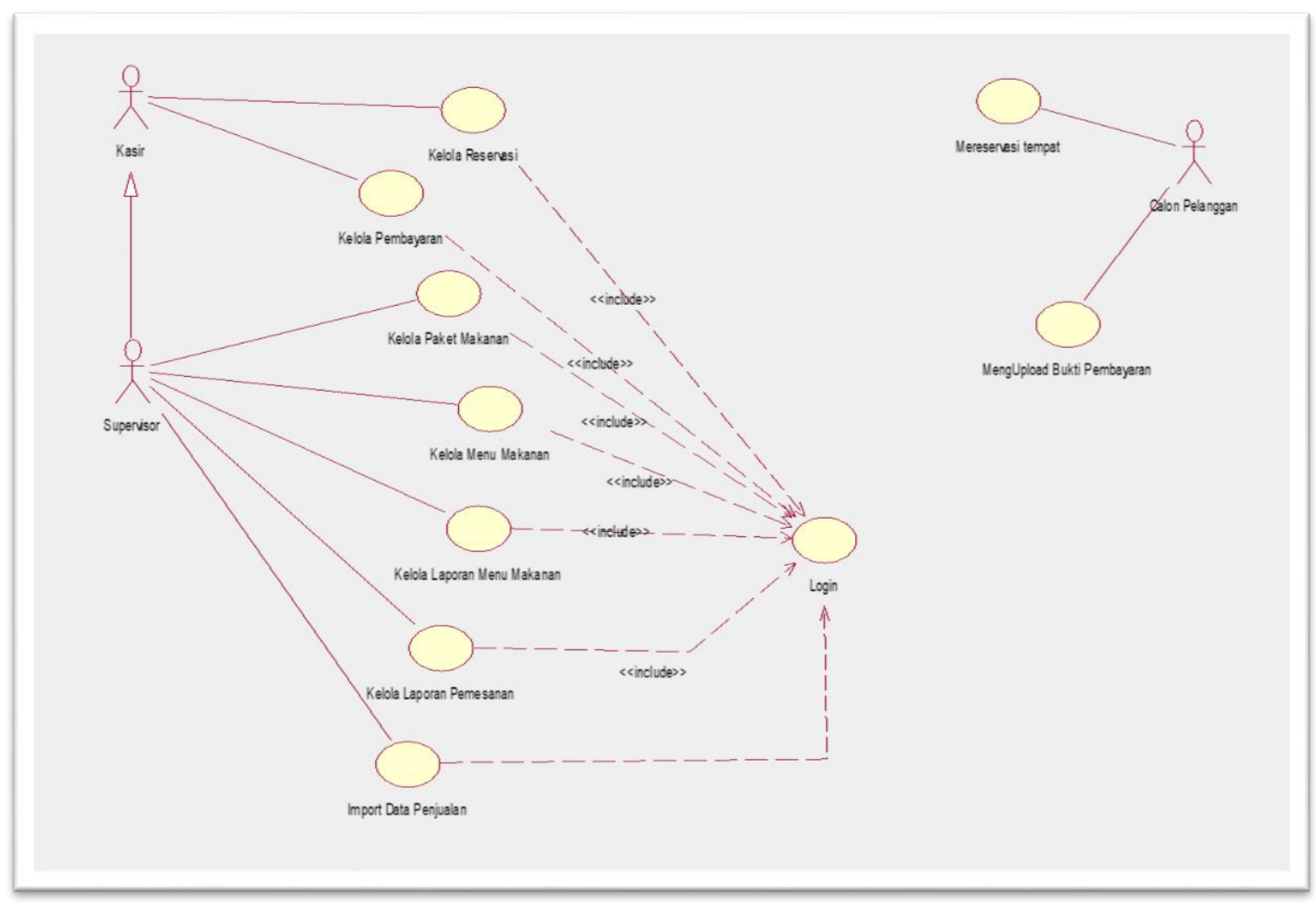

Gambar 1. Usecase Diagram 


\section{Analisa Dan Perancangan}

Dalam penelitian ini mengumpulkan data digunakan prototype, juga untuk mengolah data menjadi sebuah hasil prediksi minat konsumen dengan digunakan K-Means Clustering. Dapat dilihat pada gambar 3 .

\section{Identifikasi}

Pada aktivitas ini dimulai dengan membuat cerita-cerita atau gambaran yang diberikan narasumber yang kemudian akan menjadi gambaran dasar dari sistem.

\section{Perancangan}

Mengatur pola logika dalam sistem, design yang baik dapat mengurangi ketergantungan antar setiap proses pada sebuah sistem. Untuk melihat fungsi-fungsi yang dibutuhkan pada sistem dapat dilihat pada gambar 2. Dan class-class yang dibutuhkan oleh sistem dapat dilihat pada gambar 3.

\section{Penulisan Kode}

Setelah menyelesaikan pengumpulan cerita dan perancangan untuk aplikasi secara keseluruhan, prototype lebih merekomendasikan untuk membuat modul unit tes terlebih dahulu agar setiap cerita atau gambaran dari narasumber dapat di uji terlebih dahulu.

\section{Pengujian Kode}

Menguji semua elemen-elemen perangkat lunak yang dibuat apakah sudah sesuai dengan yang diharapkan. Prototype menerapkan perbaikan masalah kecil dengan sesegera mungkin akan lebih baik ketimbang menyelesaikan masalah saat di tenggang akhir.

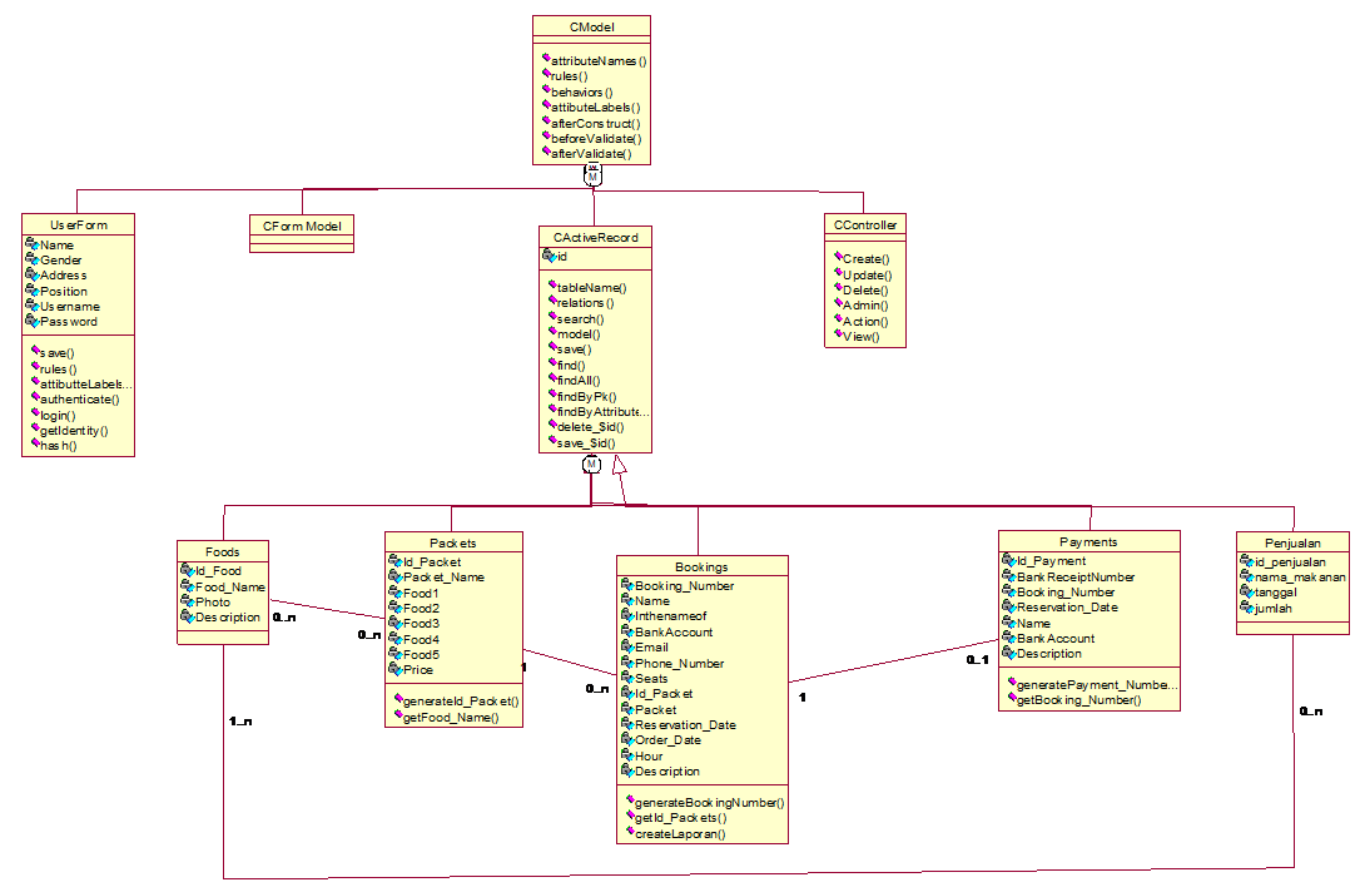

Gambar 2. Class Diagram

\section{Implementasi}

Dalam mengimplementasikan perangkat lunak agar berjalan dengan semestinya, maka perlu disusun sebuah optimalisasi yang dapat membantu proses implementasi penentuan rute terpendek sehingga dapat berjalan dengan baik. Dibahas mengenai letak fisik komponen komponen yang digunakan dengan penggambarannya menggunakan Deployment Diagram.
Deployment Diagram adalah diagram yang dapat digunakan untuk menggambarkan detail bagaimana komponen akan diimplementasikan dalam infrastruktur sistem. 

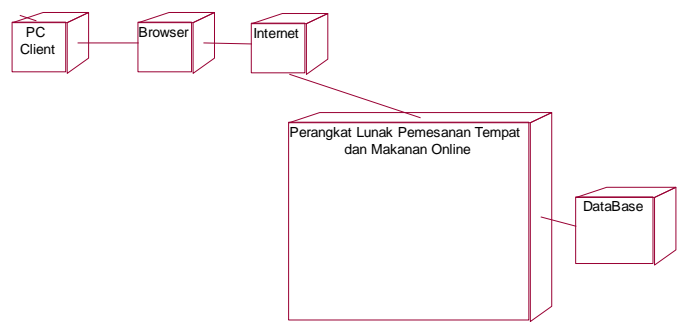

Gambar 3. Deployment Diagram

Pada diagram diatas menjelaskan tentang perangkat keras yang terlibat dalam sistem ini, yaitu komputer client, internet, yang terdapat komponen berupa browser.

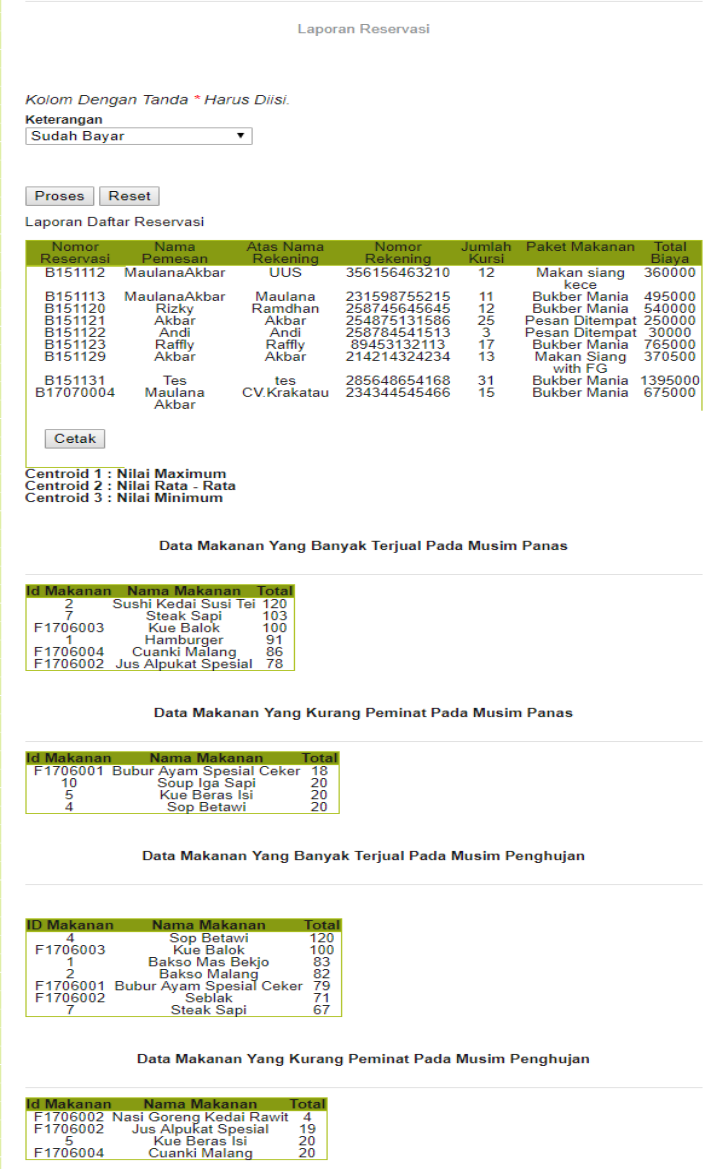

Gambar 4. Hasil Implementasi

Berikut adalah hasil dari implementasi K-Means dimana hasil akhirnya telah didapatkan dan semua menu makanan telah dikelompokkan berdasarkan nilai perhitungan centroidnya.

Prediksi Menu makanan telah didapatkan dengan dua buah clustering yaitu makanan banyak terjual dan kurag terjual permusimnya. Penentuan centroid pun sudah sesuai dengan hasil yang ingin dicapai.

\section{Penutup}

Berdasarkan uraian pembahasan pada bab-bab sebelumnya, maka ditarik bebarapa kesimpulan yang diantaranya :

1. Pengimplementasian algoritma K-Means Clustering pada menu makanan berdasarkan data penjualan dapat dilakukan dan hasil yang didapat sesuai dengan apa yang diharapkan yang berupa laporan untuk menjadi bahan pertimbangan bagi manajemen tingkat atas untuk menentukan menu makanan sesuai dengan musim. Penerapan algoritma K-Means pada Perangkat lunak Pemesanan dan Tempat Makan Online telah sesuai dengan kriteria yang dimiliki K-Means clustering, dimana data menu makanan yang diminati dan menu makanan yang tidak diminati bisa ditemukkan oleh K-Means dan hal tersebut dapat membantu pihak restoran agar tidak mengalami kerugian yang dikarenakan adanya bahan makanan yang tidak terpakai.

2. Hasil dari perhitungan algortima K-Means dapat dijadikan sebagai produk yang disarankan karena data yang diambil didapatkan dari cluster pertama yaitu cluster yang kriterianya adalah produk yang banyak terjual atau dalam hal ini adalah produk yang banyak dibeli oleh konsumen. Hal tersebut pula berhasil diimplementasikan, serta hasil K-Means tersebut juga dapat menjadi daya jual untuk memperlihatkan atau mengenalkan menu makanan terbaik yang dimiliki oleh restoran. Dalam hal ini dapat disimpulkan data yang didapat dari hasil perhitungan $\mathrm{K}$ means dapat dijadikan menu rekomendasi untuk pelanggan agar pelanggan dapat mengetahui menu rekomendasi dari pihak restoran.

\section{Daftar Pustaka}

[1] J Han and M. Kamber, Data Mining: Concepts and Techniques, Second Edition. San Francisco: Morgan Kaufmann, 2006.

[2] A. H. Nasution and Prasetyawan, Perencanaan dan Pengendalian Produksi. Yogyakarta: Graha Ilmu, 2008.

[3] Barry Render, Jr Ralph M.Stair, and Michael E.Hanna, "Quantitative Analysis for Management," in Chapter 5 
Forecasting. United State of America: Pearson Education, Inc, 2006, pp. 169183.

[4] Alda Raharja, Wiwik Angraeni, and Retno Aulia Vinarti, "Penerapan Metode Exponential Smoothing untuk Peramalan Penggunaan Waktu Telepon Di PT. Telkomsel DIVRE3 Surabaya," SISFO Jurnal Sistem Informasi, 2010.

[5] Mohammad Abdul Mukhyi. (2008) mukhyi.staff.gunadarma.ac.id. [Online]. http://www.mukhyi.staff.gunadarma.ac.i d/Downloads/files/9309/FORECASTIN G.pdf 